\title{
Research on the Status of Transnational Networking Project and the Comprehensive Benefits Analysis
}

\author{
Yunqi ZHAO ${ }^{1, a}$, Fan WU ${ }^{2, b, *}$ \\ ${ }^{1}$ State Grid Energy Research Institute, Beijing, 102206, China \\ ${ }^{2}$ Department of Economics and Management, North China Electric Power University, Baoding, \\ 071003, China
}

aemail: zhaoyunqi1129@126.com, bemail: 781316832@qq.com, ${ }^{*}$ corresponding author

Keywords: Transnational networking project, Grid integration, Benefits analysis

\begin{abstract}
With the development of technology, strengthening cooperation in the field of energy among regions is proved to be one of the main trends in power industry. It is grounded on such background that this paper focuses on the subject of transnational networking project, which can effectively promote the rational allocation of power resources and the balance of regional power industry. The current status of the construction of transnational networking project is systematically introduced in this paper from a global perspective, and then, this paper analyzes the benefits of the construction of the transnational networking project from three aspects: economic benefit, social benefit and environmental benefit. Based on the facts above, a series of factors which will influence the benefits of the project are discussed respectively as well, which aims at providing a certain reference for the government, power sectors or other stakeholders when carrying out related activities.
\end{abstract}

\section{Introduction}

With the rapid development of the global economy, the consumption of the energy has also increased rapidly year by year. And the extensive use of the traditional fossil fuels has lead to a series of challenges, such as the shortage of resources, which may threaten the survival of human sooner or later. So promoting the development of clean energy and raising energy efficiency are vital to the sustainable development of our society[1]. As a kind of clean secondary energy, the proportion of electric power in the structure of energy consumption increases gradually and it plays an important role in the energy industry, because the clean electric power has a positive impact on reducing the consumption of the fossil fuels and optimizing energy structure. Thus, the construction of the global energy interconnection can effectively increase the transmission efficiency of power resources and promote the transformation of energy structure, which provides an efficient solution for the sustainable development of the global energy. And the transnational interconnected power grids are constructed to ensure the transmission of electric energy from regions with sufficient power resource to electric deficiency areas and achieve the rational allocation of power resource, which is of great significance for improving people's life quality along the line and accelerating regional economic growth.

Compared with the general domestic networking project, transnational networking project is much more complex and systematic and a series of economic, environmental and social benefits will be emerged by the construction of this project. However, a variety of factors also need to be considered comprehensively during each period of the construction of the transnational networking project to ensure the smooth implementation of the project. Concentrated on the subject of transnational networking project, this paper makes a comprehensive introduction of present situation and the developing trend of transnational networking project and on this foundation, the economic, environmental and social benefit, as well as its influence factors are analyzed respectively, which can provide references and decision support for the government, power sector and other stakeholders when they carry out related activities. 


\section{Status Analysis of Transnational Networking Project}

So far the total length of the power grid around the world is about 75 million $\mathrm{km}$, where the length of the transnational power grid is close to 10 thousand $\mathrm{km}$. And the capacity of transnational networking is about 250 million KW, which is expected to reach 330 million KW in 2020[2]. The advancement of economic globalization urges the marketization of energy sector and the interconnection of power grids has become an emerging subject of power industry in all countries. China, for example, has carried out transnational networking project actively. The first $110 \mathrm{KV}$ voltage interconnection project between China and Vietnam was constructed and put into operation in 2004, which is the first power interconnection project of our country participating in the Great Mekong Subregion(GMS)'s cooperation[3]. Up to now, China has carried out a series of transnational networking project with neighboring countries, such as Russia, Mongolia, Myanmar, etc. Taken as a whole, the transnational networking project of Europe, North America and parts of South America started relatively early and the degree of grid interconnection of these areas is also much more higher. On the contrary, the power grid interconnection project in Asia and Africa is still at an early stage, but in recent years, the process of transnational networking project in Afro-Asian Region has achieved remarkable results. With the development of the power technology and the electricity market, five large-scale regional interconnected power grids will be formed in the future according to the distribution of power supply and load center, including Asia, Europe, North America, South America and Africa. So this paper will make a brief introduction about the current situation of transnational networking in the whole world by regions.

Status of Transnational Networking Projects in Asia. As the largest power load center, Asia has abundant renewable energy resources, such as north China and Mongolia's wind power and solar power, Siberia region's hydropower and so on[4]. Through the construction of the transnational power grid, the clean power energy will be introduced to the power grid and a super interconnected power grid, connecting the major load centers in Asia, will be constructed in the near future and then, China, Japan , South Korea, Russia and other countries in Asia will be included into the super power grid, realizing the electric power supply from the power center to the load center, which effectively improves the efficiency of the use of resources. The transnational power grid interconnection in Asia is still at its preliminary stage and currently, there is no large-scale transnational interconnected power grid in Asia, but a series of transnational networking projects have been carried out among Asian countries, such as the 500kV HVDC project between Thailand and China, the $500 \mathrm{kV}$ DC networking project between Ethiopia and Kenya, the $\pm 250 \mathrm{kV}$ DC networking project between Malaysia and Indonesia and so on.

Status of Transnational Networking Projects in Europe. As one of the areas owing highly interconnected power grid, the European grid is mainly formed by five parts: the continental power grid, Nordic grid, Baltic power grid, British grid and Irish power grid. Beyond that, there are still two independent power systems in Europe, Iceland and Cyprus power system. In 2008, the concept of "European Super grid" was proposed to construct a pan European power grid, aiming at building an interconnected and synchronous power grid to promote the reasonable allocation of various types of power resources in the European region. By 2013, there are 340 interconnected power lines among European countries, including 318 AC lines and 22 DC lines, and the quantity of exchange electricity among European countries reaches 387.3 billion $\mathrm{kW} \cdot \mathrm{h}$. For example, the $380 \mathrm{kV}$ transmission project between Holland and Germany was carried out in 2014, and other transnational networking projects, such as the $\pm 500 \mathrm{kV}$ DC submarine cable transmission project between Sweden and Lithuania, the $\pm 320 \mathrm{kV}$ flexible DC networking project between France and Italy, has also been launched in recent years.

Status of Transnational Networking Projects in South America. South America has a wealth of energy resources: Venezuela has rich oil and gas resources; Brazil has plentiful hydropower resources and great potential of wind energy; Bolivia owes abundant natural gas. Based on the facts above, there are going to achieve three main targets through the construction of transnational networking: power interconnections among countries on the West Coast, North-South electric 
transmissions in the eastern regions and East-West electric transmissions in the central regions. And the degree of grid interconnection in South America is also much more higher than other regions. For example, the Siepac networking project, an investment of 494 million dollars, can bring a series of countries or regions along the route into the interconnected power grids, including Guatemala, Salvatore, Honduras, Nicaragua, Costa Rica, etc. And the trading capacity will reach 300 MW [5]. The Connect 2022 initiative, as an important part of the regional energy network, was put forward in 2012. In addition, a series of transnational networking projects have been put into operation, including the $500 \mathrm{kV}$ back-to-back DC networking project between Brazil and Uruguay, The 500kV transmission project between Brazil and Argentina, etc.

Status of Transnational Networking Projects in North America. The North American power grid, including the United States, Canada and Mexico, mainly consists of four subsystems: Eastern power grid, Western power grid, Texas power grid and Quebec power grid. Among the four synchronous power grid, the Eastern power grid of North America is connected with the Western power grid through six DC power lines and there are also four DC power lines and a set of frequency transformer between the Eastern power grid and the Quebec power grid. In addition, another two DC power lines are established between the Texas power grid and the Eastern power grid. And there are more than 100 transmission lines between the United States and the seven provinces of Canada and the power exchange capacity between the two countries has reached 20 million $\mathrm{kW}$.

Status of Transnational Networking Projects in Africa. As the concentrated region of developing country, Africa has a large demand for power resources. Sometimes there are not enough power supply to meet the great demand of electric power, due to its weak power infrastructure and power grid. However, Africa contains a large number of clean energy, such as hydropower, solar power, wind power and so on. And it is of great significance to construct a transnational interconnected power grid, which can improve the utilization efficiency of each clean energy and balance the development of power industry in different countries. The South Africa interconnected power grid was established in 1995, and the alliance consists of 12 member states, among which nine of the members have constructed the interconnected power grid, except for Malawi, Angola and Tanzania. And this interconnected power grid provides effective guidance for transnational power networking in Africa. And the Nile Equatorial Lakes Subsidiary Act Program(NELSAP) proposed in 2013, which is still under construction, has greatly promoted the common development of power industry in Africa.

\section{Benefits Analysis and the Corresponding Influencing Factors}

The Benefits of Transnational Networking Project. Economic Benefits. From the perspective of technical and economic evaluation, the economic benefits of transnational networking project can be divided into two categories: financial benefits and national economic benefits. Financial benefits refers to the total difference between the income and the cost during the whole life cycle of the transnational networking project. Based on the accounting data and financial statements, the financial benefit of the project contains profit ability, operating capacity and debt paying ability. The net present value, internal rate of return and other financial indicators are usually applied to the analysis of the financial benefits of the project. The national economic benefit is to measure the economic benefits of the project with a macroscopic perspective, which takes the long-term effect on the national economy into consideration, including the increase of state revenue, foreign exchange receipt and disbursement, national economic growth, labor employment, etc.

Social Benefits. Social benefit refers to the positive effects on the social development that people's practice brings. And the social benefit generated by the transnational networking project mainly contains the following aspects: Firstly, the construction of the project can effectively guarantee the power supply and the rational allocation of power resources, which remarkably promotes the improvement of people's living standard along the line; Secondly, the implementation of the project helps to promote exchanges among the countries and ensure the development of the state relations; Thirdly, the development of the transnational networking project can create a large 
number of jobs for the countries or regions along the route.

Environmental Benefits. As a kind of clean secondary energy, electricity has a significant impact on reducing the pollution and protecting the environment. And the environmental benefit of transnational networking project mainly contains two aspects, direct environmental benefit and indirect environmental benefit. The direct environmental benefit of the transnational networking project is that it can reduce the use of fossil fuels and the emissions of pollutants, such as wasted water, gas and residue. Meanwhile, the construction of clean electrical energy grid-connected system contributes to reducing the emission of carbon dioxide. In addition, transnational networking project can also produce a series of indirect environmental benefits, such as reducing the coal losses during transportation, saving land resources occupation and so on.

Analysis of the Corresponding Influencing Factors. As the technology-intensive and capital-intensive industry, networking project usually has larger investments and longer construction period with higher risk than other projects. For transnational networking project, the factors involved in the project are much more complicated than general domestic construction projects because several countries along the route will be brought into the project, which makes the uncertainty of the project increase as well. All of the factors, such as state relations, geopolitics, cultural difference and so on, need to be taken into consideration during the planning and construction of transnational networking project to guarantee the implementation of the project in each stage. Combining the characteristics of the project, the factors influencing the benefits of the project are analyzed in this part, and then this paper will delete an analysis of factors influencing the benefits of the transnational networking project as well, which can provide certain references and guidance for the government, power sectors and stakeholders when carrying out the related activities.

Factors Affecting the Economic Benefit. State Relations. Carrying out the networking project among different countries is one of the remarkable features of transnational networking project, which means the state relation will have a significant impact on the economic benefit of the project. Stable and sound state relations can effectively promote the implementation of the project and have a positive impact on the economic benefit of the project. On the contrary, the deterioration of state relations will inevitably have a negative influence on the economy of the project, which may lead to the delay of the construction, interruption, etc[6].

Economic Situation. Transnational networking project, as a large-scale power construction project, requires higher investment compared with other general projects, And the favorable economic situation provides guarantees for the fund raising and the operation of the project, which brings better economic benefits to the project[7]. But due to the financial burden of the government or the inflation, these factors will produce a negative impact on the economic benefit of the project when the economic situation of the countries involved in the project presents a negative trend.

Exchange Rate Fluctuation. The project is carried out among different countries at the same time, so the exchange rate is involved in the factors influencing the economic benefits of the transnational networking project. The exchange rate fluctuation, which is probably caused by balance of payment, inflation, interest rate changes or other factors, will change the price of the related commodity at home and abroad, influencing the revenues, costs and cash flows of the project, which would directly influence the economic benefits of the project[8].

Market Factors. For the transnational networking project, the influence of the market factors on the economic benefit can be considered from the following aspects: 1) The influence of production factor market. Changes of supply and demand in production factor market will lead to the price fluctuations, which has an important impact on the construction cost and directly influence the economic benefit of the project; 2) The influence of the electricity market. With the development of the electricity market, the increasing uncertainty of the demand for electrical energy brings risks to the sales of electricy, which has an impact on the economic benefit of the project as well; 3) The influence of power engineering market. The power engineering market with different development levels makes the market have different levels of competition, which, eventually leads to the construction cost of the project varies from each other. 
Factors Affecting the Social Benefit. The Scale of the Project. One of the main social benefits of the transnational networking project is that it can provide a large number of jobs for the regions along the route. And the scale of the project determines the amount of jobs that the project can provide. And the larger the project scale is, the more jobs it can create. However, it is determined by a series of complex factors, such as the limitation of the capital, resource distribution, the further analysis is unavailable in this paper due to the limitation of space.

Power Technology Level. During the planning and construction of the transnational networking project, the power technology level has an impact on the social benefit of the project as well. For example, the quality and efficiency of the power supply can be greatly improved with the development of the power technology, which ensures the security of electricity supply and the improvement of the living standard along the route.

Public Participation and Involuntary Resettlement Problems. As an infrastructure project, the success of the implementation of the transnational networking project partly depends on the support of the public. The participation of the related groups contributes to maximizing the planning's quality and enhancing the social benefit emerged by the project. And involuntary resettlement refers to the immigrants who are forced to remove against their original intention, which sometimes would lead to the formation of crisis. And this phenomenon may cause a series of social problems, such as poverty, unfairness, instability and so on, resulting in the influence on the social benefit of the transnational networking project.

Factors Affecting The Environmental Benefit. Resource Distribution. Increasing the proportion of electricity consumption can severely reduce the use of fossil fuels and the emission of pollutants. And the wasted water, nitrogen oxides, carbon dioxide and other emissions can be greatly reduced through the construction of transnational networking project. However, different types of electrical sources have different influences to the environment, for example, the integration of renewable energy generation, such as hydropower, wind power, can reduce much more carbon dioxide emissions compared with traditional coal-fired power. And the resource distribution determines the types of electrical power connected to the grid, which, in other words, the distribution of the resources has an impact on the environmental benefit of the transnational networking project.

Equipment and Materials. During the construction and operation of the transnational networking project, a large number of engineering materials and power equipments are involved in the project and the selection of different types of materials or equipments will produce different impacts on the environment along the route. Take the construction materials as an example, based on the life cycle theory, the use of new environmental protection materials during the construction period can reduce the impact of pollutants, including the production process of the material.

Technical Factors. In this part, the influence of technical factors to the environmental benefit lies in the following two aspects: On the one hand, the selection of technical parameters, such as voltage level, cross-sectional of wires, has a significant influence on the line loss rate, which will influence the environmental benefit of the project as well; On the other hand, the development of the electric technology can effectively reduce the negative influence produced by the transnational networking project, such as reducing the electromagnetic radiation by the advancement of electric technology.

\section{Conclusion}

With the development of the global power industry and the change of energy consumption consciousness, increasing the utilization of clean and renewable energy becomes a trend of the power industry. And the construction of transnational networking project can promote the transmission of electric energy from regions with sufficient power resource to electric deficiency areas and balance the allocation of power resources, which can effectively increase the transmission efficiency of power resources and promote the transformation of energy structure. Concentrated on the new subject of power industry, first of all, the construction status of transnational networking project is analyzed by regions in this paper. Then, the economic benefit, social benefit and environmental benefit that the transnational networking project may produce are analyzed respectively and based on the facts above, this paper delete an analysis of factors influencing the 
benefits of the transnational networking project from three aspects: factors influencing economic benefits, factors influencing social benefits and factors influencing environmental benefits, aiming at providing certain references for the power sector, enterprises and other stakeholders to enlarge the benefit of the project and avoid the risks when carrying out the related activities, which is the practical significance of this paper.

\section{Acknowledgement}

This work was supported by the science and technology project of State Grid Corporation of China (Project Name: Research on the comprehensive evaluation method of economic, social and environmental benefits of transnational networking project).

\section{References}

[1] General Office of the State Council. The Action Plan for Energy Development Strategy (2014-2020) [EB-OL]. http://www.gov.cn,2014.

[2] BJX Power T\&D. The interconnection technology and the prospect of the interconnecting of the transnational power grid [EB-OL]. http://www.chinasmartgrid.com.cn, 2017.

[3] Zhou Hai, Long Yuhai, Liu Yu. Discussion on the construction of 110kV networking project between China and Vietnam[C]. Proceedings of Symposium on grid interconnection between China and Vietnam , 2006:85-93.

[4] BJX Power T\&D. What is the latest construction progress of the Asian super power grid under the background of energy internet[EB-OL]. http://shupeidian.bjx.com.cn, 2016.

[5] Power Engineering International. Making the Latin American connection[EB-OL]. http://www.powerengineeringint.com, 2013.

[6] Yang Liu. The evaluation of political risk in transnational investment[J]. Technology Entrepreneurship Monthly,2008(04):35-37.

[7] Zhang Shuibo, Zheng Xiaodan. The impact of economic development and the PPP system on infrastructure projects in developing countries[J]. Soft Science, 2015(07):25-29.

[8] Pan Xiaojun, Lin Zhengzhen. Research on the influence of exchange rate on state payment[J], CONSTRUCTION ECONOMY,2011:10-12. 